\title{
Elaboration of the Equipment and Technology for Cutting Rolled Round Bars and Pipes with the Cyclic Circular Bending Method
}

\author{
Aleksej Antimonov ${ }^{1}$, Sergej Poljanskij ${ }^{2}$, and Nadezhda Pushkareva ${ }^{1, *}$ \\ ${ }^{1}$ Ural Federal University, Institute of New Materials and Technologies, 620002, 19 Mira street, \\ Ekaterinburg, Russia \\ 2 "Intec" Company, 620078, 34 Mira street, Ekaterinburg, Russia
}

\begin{abstract}
A brief overview of methods for cutting round bars and pipes is presented, their main advantages, disadvantages and field of application are considered. It is proposed to use the effect of fatigue fracture for round bars and pipes breaking. The task is to study this process under the action of cyclic loads. The possibility of applying the known provisions of calculating theory of strength analysis for low-cycle fatigue for this process is tested. A comparative assessment of theoretical and experimental data is given and their significant difference is established. New calculated dependences are proposed, which are in good agreement with the experimental data. A theoretical assessment of the productivity of the process of round bars and pipes breaking by the method of cyclic circular bending was carried out using new results and various options for the design of a device for breaking were considered with an analysis of the features of their operation. Based on the results of the analysis, a variant of the device for the implementation of a continuous process of breaking the pointed ends of thick-walled fuel pipes during drawing in coils and a diagram of the mechanism for breaking the ends of the pipe with its supply from the coil were selected. Samples of pipes obtained by brittle cyclic bending are presented.
\end{abstract}

\section{Introduction}

The metallurgical industry supplies machine-building plants with round bars and long pipes. Rolled steel with a diameter of up to $9 \mathrm{~mm}$ inclusive is made in coils, and over $9 \mathrm{~mm}$ - in bars with a length of 1 to 12 meters [1]. The length of hot-deformed steel pipes is 4-12 meters [2]. At the blank sections of machine-building plants, rolled products and pipes are cut to lengths according to the dimensions of the loading part of the machines. When mass and large-lot manufacture of small parts such as rollers and bushings on automatic machines with loading of blanks from hopper devices, it is necessary to ensure high productivity of the cutting process and the durability of the cutting tool.

Cutting of rolled products and pipes is carried out by different methods [3-5]. Blade tools are widely used - band and circular saws [6]. The use of this tool in this case is limited by its

* Corresponding author: nbpush@mail.ru 
high cost, low tool life and low productivity of the cutting process. To restore the cutting ability, regrinding with the use of special equipment is required.

The advantage of the process of cutting steel with an abrasive tool is high productivity [7]. Abrasive wheels on a bakelite bond are cheap, but the consumption due to the wear of the tool is quite large, which in the end equates it with the price of a razor tool. The disadvantage is the high temperature in the cutting area, especially when cutting pipes. A jet of hot abrasive grains and molten metal enters the inside of the pipe. The abrasive is welded to the inner surface. This requires subsequent cleaning of the workpieces. In addition, cutting with razor and abrasive tools generates waste in the form of chips and abrasives, which must be disposed of.

Waste-free methods include shifting and bending breaking of round bars, the use of which ensures high productivity [8.9]. In this case, a cheap tool, durable to destruction and deterioration, is used in form of a simple design dies. At the same time, these methods can't be used for pipes breaking because there are cross-sectional defects that are formed while breaking by shifting and bending.

Laser, plasma and waterjet cutting are used to process materials in complex technological processes on numerically controlled machines and are not intended for cutting bars and pipes into workpieces [10-13].

\section{Purpose of work}

Elaboration and research of high-performance process and equipment for cutting bars and pipes without the use of abrasive and blade cutting tools. Study of the possibility of replacing the cutting process with a brittle one based on the effect of fatigue failure.

\section{Formulation of the problem}

Fatigue of materials is the cause of the destruction of machine parts and structural elements [14]. Under the action of cyclic loads, a fatigue crack appears in the material, with the development of which the cross-sectional area of the part gradually decreases, and the stress in it increases. When the voltage reaches the fatigue limit, the part suddenly collapses. The fatigue limit depends on the material property, the presence of a stress concentrator and the surface roughness. The paper proposes to use the effect of fatigue fracture for breaking round bars and pipes with a study of the productivity of this process.

\section{Breaking process diagram}

The process is based on the breaking of bars by alternating bending (see Fig. 1). One end of the bars product 1 is fixed in the clamp 3. The other end is free and under the action of the applied load makes a circular motion with a deviation from its axis. In the process of movement, the sharp edge of the tool 2 is introduced into the bar with the application of the stress concentrator 4 on its surface. The combination of the actions of alternating elastoplastic bending and notch creates a high stress concentration with a pronounced fatigue effect. This leads to the destruction of the rolled product in the notch plane. The end of the bar breaks off at a certain number of loading cycles. 


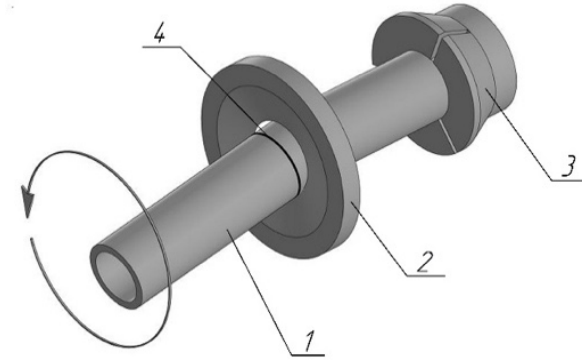

Fig. 1. Diagram of the breaking process.

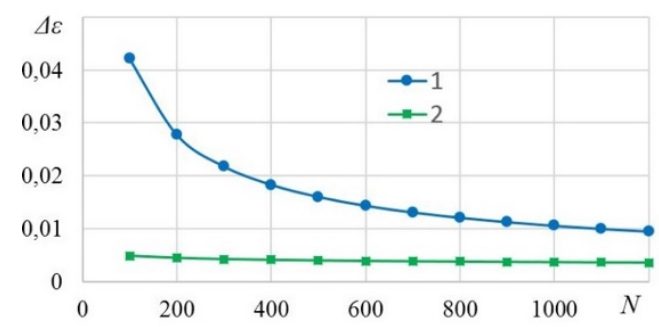

Fig. 2. Plastic 1 and elastic 2 components of the deformation range $\Delta \varepsilon$.

Such destruction in the strength theory of materials is called low-cycle fatigue [15].

\section{Theoretical outlines of low-cycle fatigue strength calculation}

Under the low-cycle fatigue conditions, cyclic elastoplastic bending of the end of the bars with a notch for stress concentration leads to its failure. The main problem of low-cycle fatigue calculations is to determine the number of cycles before material destruction. The theory of strength calculations is based on numerous experimental data from the study of the durability and fracture of materials under the action of cyclic elastoplastic deformations. Based on the results of processing a large amount of experimental data when testing various materials, the following dependence is proposed [16]:

$$
\Delta \varepsilon=\varepsilon_{p}+\varepsilon_{e}=\left(\ln \frac{1}{1-\psi}\right)^{0,6} N^{-0,6}+3,5 \frac{\sigma_{\mathrm{B}}}{E} N^{-0,12},
$$

where $\Delta \varepsilon=\varepsilon_{\max }-\varepsilon_{\min }-$ deformation range, $\varepsilon_{\max }$ и $\varepsilon_{\min }-$ max and min loading cycle amplitudes, $N$ - number of cycles to destruction, $\psi$ - relative constriction in the pin upon sample rupture, $\sigma_{\mathrm{в}}$ и $E$ - tensile strength and modulus of elasticity of the material.

The first term in this formula the plastic component of deformation $\varepsilon_{p}$ is determined, and the second term is the elastic component $\varepsilon_{e}$. Calculations according to formula (1) for mild steel with a carbon content of $0,2 \%$ at $\psi=0,55 ; \sigma_{\mathrm{B}}=460 \mathrm{MPa} ; \quad E=1,9 * 10^{5} \mathrm{MPa}$ are presented at Fig. 2. As follows from the figure, the main effect on fracture at a small number of cycles is exerted by the plastic component of the deformation amplitude. Thus, at $N=100, \frac{\varepsilon_{p}}{\varepsilon_{e}}=11,3$ and at $N=1200, \frac{\varepsilon_{p}}{\varepsilon_{e}}=3,4$. Experiments with many materials show that the influence of the elastic component becomes noticeable at $N=(1 \div 20) * 10^{3}$. Considering that the expected number of cycles in the breaking process will be significantly less, the elastic component can be neglected in the calculations. Then equation (1) for determining the range of deformation will take the form:

$$
\Delta \varepsilon=\varepsilon_{p}=\left(\ln \frac{1}{1-\psi}\right)^{0,6} N^{-0,6} .
$$

\section{Experimental research}

Investigations of the materials strength by cyclic elastoplastic deformations in general are carried out under a homogeneous stress condition, which is realized under uniaxial tension and compression. The conditions for the process of bars breaking by cyclic bending with a 
notch for stress concentration differ significantly from laboratory tests of samples under a homogeneous stress condition, therefore, for practical calculations the possibility of using formula (2) requires experimental verification. This test was carried out by breaking thickwalled pipes made from mild steel with a carbon content of $0,2 \%$ [17]. Experimental data on the dependence of the range of deformation $\Delta \varepsilon$ on the number of cycles $\mathrm{N}$ to failure for pipes with different mechanical properties, diameter and wall thickness are shown in Fig. 3. Comparison of the results of calculations by formula (2) with experimental data is shown in Fig.4.

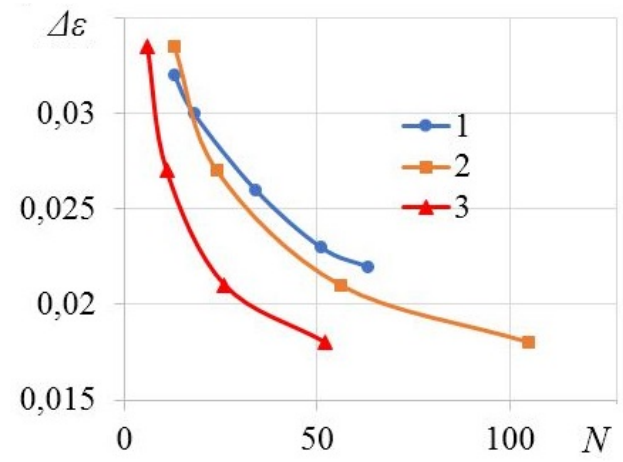

Fig. 3. Experimental data of the dependence of the range of deformation on the number of cycles to fracture.

Pipes sizes, mm: $1-9,6 \times 2,95, \psi=60$;

$2-13 \times 3,32 \psi=60 ; 3-13 \times 3,32, \psi=40$.

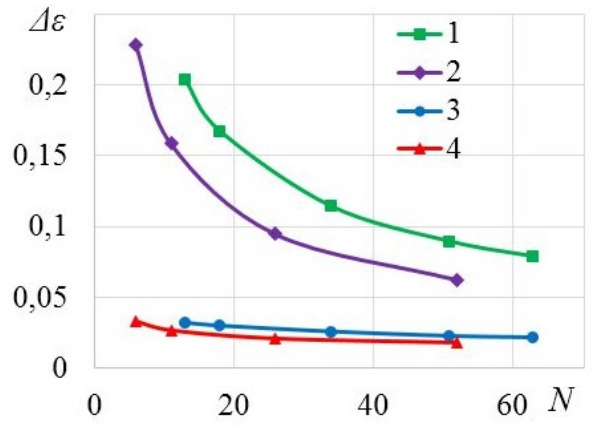

Fig. 4. Comparison of the calculation results using the formula (2) with experimental data. 1 and 2 - calculation, 3 and 4 - experiment Pipes sizes, mm: 1 and $3-9,6 \times 2,95, \psi=60$; 2 and $4-13 \times 3,32, \psi=40$.

As follows from the figure, there is a significant difference between the calculated and experimental data. For a small number of cycles, the calculation results are six or more times higher than the experimental data.

\section{Evaluation of the productivity of the rolled steel breaking process}

The similarity of the curves in Fig. 3 and Fig. 4 for the calculated and experimental data shows that the qualitative dependence of the deformation range on the number of cycles before failure is the same in both cases. The formula for calculations gives a good agreement between the calculated and experimental data, and has the form

$$
\Delta \varepsilon=\frac{1}{16}\left(\ln \frac{1}{1-\psi}\right)^{0,26} N^{-0,26} .
$$

Comparison of calculations by this formula with experiment is shown in Fig. 5. The difference between the calculated and experimental data does not exceed $7 \%$. 


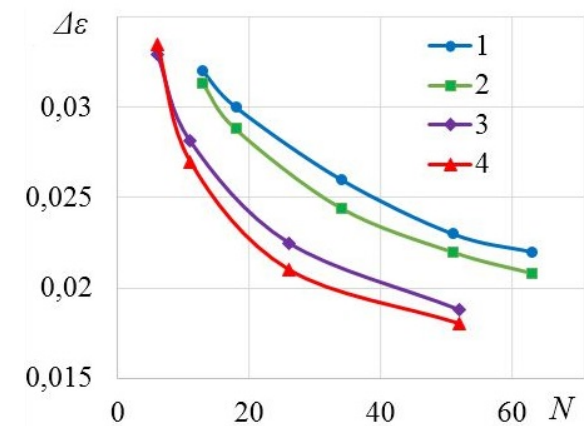

Fig. 5. Comparison of calculation results by formula (3) with experimental data.

1 and 4 - experiment, 2 and 3 - calculations.

Pipes sizes, mm:

1 and $2-9,6 \times 2,95, \psi=60$;

3 and $4-13 \times 3,32, \psi=40$.

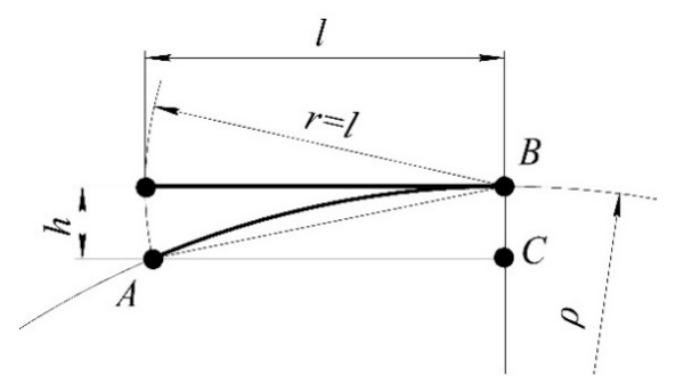

Fig. 6. To determine the radius of curvature.

Let us use this formula to assess the productivity of the rolled steel breaking process. Then equation (3) for determining the number of cycles before failure will be as follows:

$$
N=\ln \frac{1}{1-\psi}\left(\frac{1}{16 * \Delta \varepsilon}\right)^{\frac{1}{0,26}}
$$

The deformation range will be defined as the relative deformation during bending of the balk [18]

$$
\varepsilon=\frac{\mathrm{y}}{\rho},
$$

where $\mathrm{y}-$ is the distance from the neutral line (axis) of the balk to some point in the cross section, $\rho-$ the radius of curvature of the neutral line.

Let us assume that the neutral line is part of the circle and $\rho=$ const. Define the radius of curvature through the deflection $h$ at the end of the rolled metal and the length 1 that protruding beyond point $\mathrm{B}$, i.e. beyond the tool (see Fig. 6). Let the point $\mathrm{O}$ of the center of the neutral line curvature be located on the continuation of the line $\mathrm{BC}$. Then from the equality of the sides $\mathrm{AC}$ of triangles $\mathrm{ABC}$ and $\mathrm{AOC}$ we obtain

$$
\rho=\frac{l^{2}}{2 h} \text {. }
$$

The maximum deformation occurs on the outer surface when $y=D / 2$.

In this case

$$
\varepsilon=\frac{D h}{l^{2}} .
$$

To assess the possibility of using expression (7), we used the data of [17], in which the magnitude of the relative deformation was determined by the method of coordinate grids. The mesh was applied to the outer surface of the pipe samples, which were then bent. According to the experimental data, the dependence of the deformation on the ratio of the deflection $\mathrm{h}$ to the overhanging length 1 and the pipe diameter $\mathrm{D}$ was obtained.

$$
\varepsilon=3,271(h / l)^{0,773}+(D / 2)^{0,546} .
$$


The calculation results using formulas (7) and (8) for pipes of various sizes are presented at Fig. 7. The difference in the calculated and experimental data does not exceed $18 \%$.

This makes it possible to use formula (7) to determine the range of deformation. The calculated value $\varepsilon$ in this formula should be considered as the amplitude of the deformation cycle. For example, with a symmetric loading cycle for the deformation range we will have

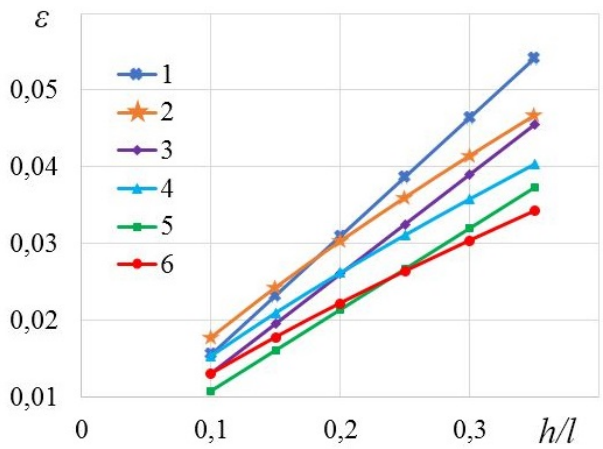

Fig. 7. Comparison of results calculations using formulas (7) and (8) for pipes of different sizes. $1,3,5$ - calculations by the formula (7); $2,4,6$ - calculations by the formula ( 8 ) Pipes sizes, $\mathrm{mm}: 1$ and $2-17 \times 3,7$; 3 and $4-13 \times 3,35 ; 5$ and $6-9,6 \times 2,95$.

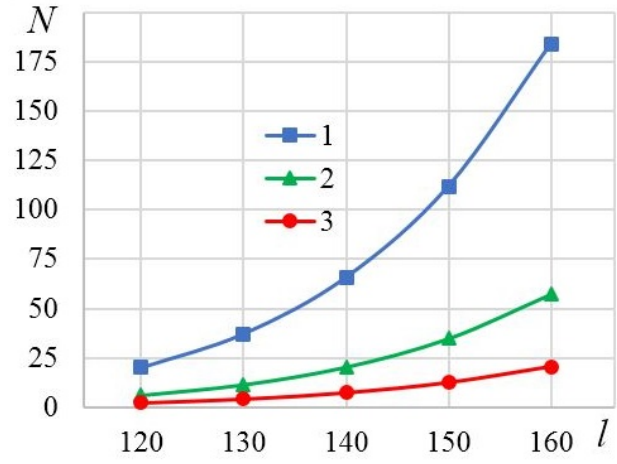

Fig. 8. The results of calculating the number of cycles before failure according to the formula (11). Pipes sizes, $\mathrm{mm}$ :

$1-9,6 \times 2,95$;

$2-13 \times 3,35$;

$3-17 \times 3,7$.

$$
\Delta \varepsilon=\varepsilon_{\max }-\varepsilon_{\min }=2 \varepsilon=\frac{2 D h}{l^{2}}
$$

Then, for an asymmetric loading cycle, we obtain

$$
\Delta \varepsilon=\frac{D\left(h_{1}-h_{2}\right)}{l^{2}}=\frac{D \Delta h}{l^{2}},
$$

where deflections $h_{1}$ and $h_{2}$ depends on the type of stress cycle.

Finally, the formula to calculate the number of cycles before failure will take the form

$$
N=\ln \frac{1}{1-\psi}\left(\frac{l^{2}}{16 D \Delta h}\right)^{\frac{1}{0,26}},
$$

The results of calculating according to this formula for pipes of various sizes, depending on 1 at $\Delta h=42 \mathrm{~mm}$, are presented at Fig. 8 .

\section{Design of devices for rolled products breaking}

As noted earlier, in the process of breaking by cyclic bending, the end of the rolled bars must be set to move along a circular path. Such movement can be carried out by devices of various designs. The scheme of operation of one of them is presented at Fig. 9. The device consists of a disk 1 with a hole 2 . At the initial moment, the disk is installed in position $I$, in which the axis of the hole is aligned with the axis of the rolled product. Then the disc moves to position II until the disc axis aligns with the bar's axis in clamp 3 at Fig. 1. The disc starts to spin at a frequency $\omega$. The end of the bar makes a circular motion with a bend in a symmetrical cycle. The disadvantage of the design is the need to stop the disk in a certain 
position to align the axes of the rolled bar and the hole, as well as the periodic movement of the disk from one position to another during breaking each workpiece.

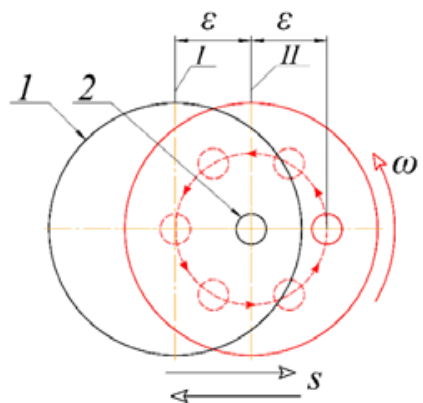

Fig. 9. Disc with hole.

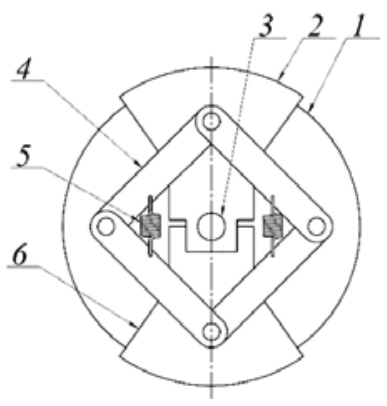

Fig. 10. Disk with load.

The Figure 10 shows a design that does not have these drawbacks [19]. The device consists of a disc 1 . It carries a load 2 with a hole 3 , a lever system 4 with springs 5 and a counterweight 6 . When the disc does not rotate, the hole and the bars are always coaxial.

The end of the roll can be freely inserted into the hole. The bending of the end of the rolled product is carried out by radial movement of the load along the guides of the disk under the action of centrifugal force during the rotation of the disk. Installing a counterweight reduces dynamic loads. The lever system serves to synchronize the movements of the load and counterweight, and the springs return the load and counterweight to their original position after stopping the rotation of the disc. The end of the bars also makes here a circular motion with a bend in a symmetrical cycle. The disadvantage of this design is the need to stop the disk when breaking each workpiece, as well as determining the parameters of the device and its settings for different assortments of rolled products breaking.
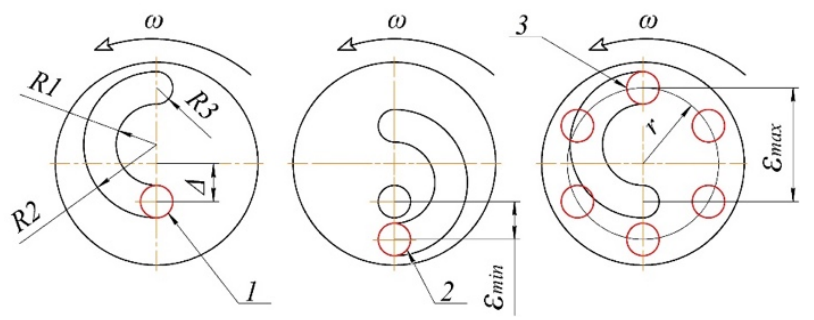

Fig. 11. Grooved disc.

To implement a continuous breaking process, we proposed a design in which the bending of the end of the rolled bars is carried out by rotating a disc with a groove ( see Fig. 11) [20]. The disc is installed with an offset $\Delta$ relative to the rolled bars axis. When disk rotates in position 1, the end of the rolled groove is gripped with its subsequent bending and movement along a circle with a radius $r$. In disk positions 2 and 3, the end of the rolled bars is deformed with minimum $\Delta \varepsilon_{\min }$ and maximum $\varepsilon_{\max }$ amplitudes. The disadvantage of such design is a loading in an asymmetric cycle, which is less dangerous than a symmetric cycle. 


\section{Practical application of the results}

The obtained results were used for breaking the pointed ends in the in-line production of thick-walled fuel pipes by coiled drawing [21-23]. For this, the design, manufacture and testing of devices of various designs were carried out [24]. In the technological process of drawing, it is necessary to sharpen the end of the pipe to insert it into the die with subsequent capture by the pulling device. At each transition during multi-pass drawing on a self-aligning mandrel the end of the pipe must be cut off for the introduction of lubricant and a mandrel, and then sharpened again. In this case, it is necessary to ensure a good geometry of the pipe cross-section. As noted earlier, the use of razor and abrasive tools for cutting pipes has disadvantages. Therefore, it is advisable to use a chipping to remove the pointed end. A diagram of the mechanism for of a pipe ends breaking from a coil is shown at Fig. 12.

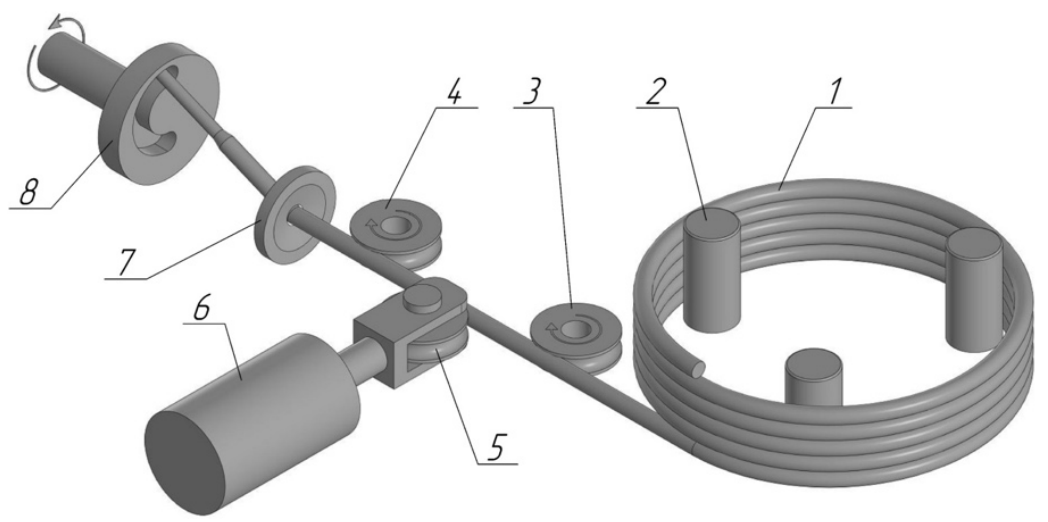

Fig. 12. Scheme of a mechanism for breaking pipe ends from a coil.

Coil 1 is located on the unwinding table with fixation by rollers 2 . The pipe is pulled out of the coil by the drive rollers 3, 4, straightened by bending under the pressure of roller 5 which is mounted on the cylinder rod 6, and passed through the hole in the tool 7 for notching with an emphasis on the end of the rotating disk 8. The pipe movement is stopped due to slippage in the rollers. When it coincides with the groove of the disc, the pipe moves until it stops against the bottom of the groove, deforms with a circular bend and breaks. If necessary, the breaking process can be continuously repeated without interruption.
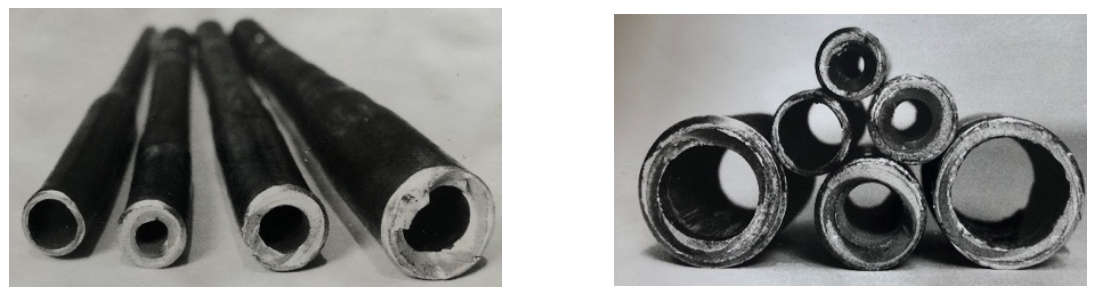

Fig. 13. Sample pipes

At Fig. 13 it is shown some pipe samples obtained by brittle cyclic bending. The figure shows that the use of the process provides good breaking cross-sectional geometry of the pipe, that is quite enough to make necessary process steps during drawing. 


\section{Conclusion}

The presented results of theoretical, experimental and development work show that a promising direction for cutting round steel and pipes is the use of breaking by cyclic circular bending without the use of edge and abrasive cutting tools.

\section{References}

1. GOST 2590-2006, Prokat kruglyj [Round rental]

2. GOST 8732-78, Prokat trubnyj_gorjachekatannyj [Tubular Hot-rolled]

3. S. I. Veselovskij, Razrezka materialov [Cutting materials] (Mashinostroenie, Moscow, 1973)

4. S.N. Poljanskij, A. M. Antimonov, V. I. Sokolovskij, Rezka holodnodeformirovannyh trub [Cutting cold formed pipes] (Chermetinformacija Institute, Moscow,1985)

5. B.V. Bondarenko, Rezka sortovogo prokata na mernye zagotovki [Cutting long products into dimensional workpieces] ( NIIMASh, Moscow,1968)

6. I. G. Kubrin, N. I. Medvedjuk, Rezanie metallov na stankah i pilah [Cutting metals on machines and saws] (Vysshaja shkola, Moscow,1966)

7. Ural.fil. VNII abrazivov i shlifovanija [Ural Branch of All-Russian Research Institute of Abrasives and Grinding], Abrazivnaja rezka stal'nyh zagotovok: Metod. rekomendacii [Abrasive Cutting of Steel Billets: Methodical Recommendations] (VNIITJeRM, Moscow,1988)

8. V. M. Finkel', Ju. I. Golovin, G. B. Rodjukov, Holodnaja lomka prokata [Cold breaking of rolled products] (Metallurgija, Moscow, 1982)

9. E. V. Filimonov, Povyshenie jeffektivnosti razdelenija sortovogo prokata na mernye zagotovki detalej tipa valikov na osnove primenenija holodnoj lomki izgibom [Increasing the efficiency of dividing long products into dimensional workpieces of parts such as rolls based on the use of cold bending breaking], $\mathrm{PhD}$ dissertation, Saratov, 2003

10. B.C. Golubev, F.V. Lebedev, Lazernaja tehnika i tehnologii, Kn.2: Inzhenernye osnovy sozdanija tehnologicheskih lazerov [Engineering fundamentals for creating technological lasers, Vol. 2: Engineering foundations for the creation of technological lasers] (Vysshaja shkola, Moscow, 1988)

11. B.C. Golubev, F.V. Lebedev, Lazernaja tehnika i tehnologii, Kn.1: Inzhenernye osnovy sozdanija tehnologicheskih lazerov [Engineering fundamentals for creating technological lasers, Vol. 1: Engineering foundations for the creation of technological lasers] (Vysshaja shkola, Moscow, 1987).

12. I.G. Shirshov, V.N. Kotikov, Plazmennaja rezka [Plasma cutting] (Mashinostroenie, Leningrad, 1987)

13. S.N. Poljanskij, A.S. Nesterov, Tehnologija i oborudovanie gidroabrazivnoj rezki [Waterjet cutting technology and equipment], Vestnik Mashinostroenija, 5, pp. 43-46 (2004)

14. V.F. Terent'ev, S.A. Korableva, Ustalost' metallov [Fatigue of metals] (Nauka, Moscow, 2015)

15. V.V. Moskvitin, Plastichnost' pri peremennyh nagruzhenijah [Plasticity under variable loads] (Moscow University Publishing House, Moscow, 1965) 
16. S. Mjenson, Temperaturnye naprjazhenija i malociklovaja ustalost' ${ }^{\text {[Thermal stresses }}$ and low cycle fatigue] (Mashinostroenie, Moscow, 1974)

17. V.I. Sokolovskij, S.N. Poljanskij, A.M. Antimonov, Prodolzhitel'nost' rezki trub pri znakoperemennom nagruzhenii [Duration of pipe cutting under alternating loading], Izvestija vysshih uchebnyh zavedenij. Chernaja metallurgija, 10 , p.34 (1988)

18. G. S. Pisarenko, A. P. Jakovlev, V. V.Matveev, Spravochnik po soprotivleniju materialov, 2-e izd., pererab. i dop. [Handbook on the strength of materials, 2-nd edition] (Naukova dumka, Kiev, 1988)

19. S.N. Poljanskij, A.M., Antimonov, V.I. Sokolovskij, G.V. Dubonosov, G.V. Araptanov, G.P. Moiseev, I.M. Raushenbah, A.V.Uhov, USSR Patent 1087272 (1984).

20. A.M. Antimonov, S.N. Poljanskij, V.I. Sokolovskij, G.P. Moiseev, I.M. Raushenbah, A.V. Uhov, USSR Patent 1140901 (1985)

21. A.M. Antimonov, A.A. Bersenev, Proizvodstvo toplivoprovodnyh trub dlja dizel'nyh dvigatelej [Production of fuel pipes for diesel engines], Stal', 3, pp. 54-55 (2009)

22. A.M. Antimonov, Mastering the production of fuel pipes for diesel engines / A.M. Antimonov, N.B. Pushkareva // High technologies. Business. Society 2018 (HTBS 2018): International scientific conference High Technologies Proceedings. (Borovets, Bulgaria, 12-15.03.2018). - Sofia, 2018. - Year II, issue 1 (3). - P. 67-70.

23. A.M. Antimonov, N.B. Pushkareva, Fuel Pipes Coil Drawing Line Production for Diesel Engines, Materials Science Forum, Vol. 946 (3), pp. $739-743$ (2019)

24. S.N. Poljanskij, A.M., Antimonov, V.I. Sokolovskij, Mehanizmy rezki kruglogo prokata [Round bars cutting mechanisms], Mashinostroitel' , 1, pp. 10-11 (1986) 